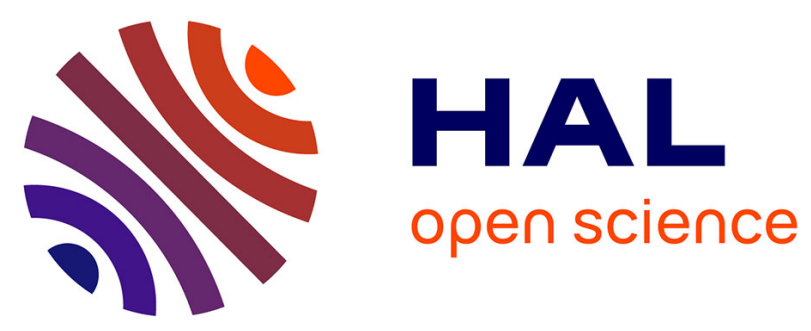

\title{
Impact of Typhimurium DT104 Virulence Factors and on the onset, clinical course, colonization patterns and immune response of porcine salmonellosis
}

Steffi Brumme, Thorsten Arnold, Haukur Sigmarsson, Jörg Lehmann, Holger C. Scholz, Wolf-Dietrich Hardt, Andreas Hensel, Uwe Truyen, Uwe Roesler

\section{To cite this version:}

Steffi Brumme, Thorsten Arnold, Haukur Sigmarsson, Jörg Lehmann, Holger C. Scholz, et al.. Impact of Typhimurium DT104 Virulence Factors and on the onset, clinical course, colonization patterns and immune response of porcine salmonellosis. Veterinary Microbiology, 2007, 124 (3-4), pp.274. 10.1016/j.vetmic.2007.04.032 . hal-00532254

\section{HAL Id: hal-00532254 https://hal.science/hal-00532254}

Submitted on 4 Nov 2010

HAL is a multi-disciplinary open access archive for the deposit and dissemination of scientific research documents, whether they are published or not. The documents may come from teaching and research institutions in France or abroad, or from public or private research centers.
L'archive ouverte pluridisciplinaire HAL, est destinée au dépôt et à la diffusion de documents scientifiques de niveau recherche, publiés ou non, émanant des établissements d'enseignement et de recherche français ou étrangers, des laboratoires publics ou privés. 


\section{Accepted Manuscript}

Title: Impact of Salmonella Typhimurium DT104 Virulence Factors $i n v C$ and $s s e D$ on the onset, clinical course, colonization patterns and immune response of porcine salmonellosis

Authors: Steffi Brumme, Thorsten Arnold, Haukur

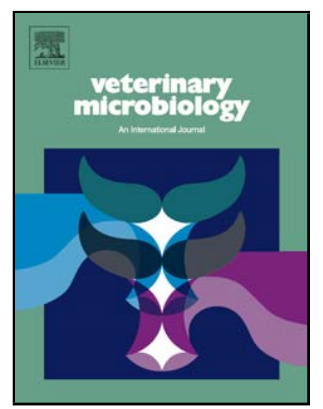

Sigmarsson, Jörg Lehmann, Holger C. Scholz, Wolf-Dietrich

Hardt, Andreas Hensel, Uwe Truyen, Uwe Roesler

PII: $\quad$ S0378-1135(07)00214-3

DOI: $\quad$ doi:10.1016/j.vetmic.2007.04.032

Reference: $\quad$ VETMIC 3674

To appear in: $\quad$ VETMIC

Received date: $\quad 16-3-2007$

Revised date: 22-4-2007

Accepted date: $\quad$ 25-4-2007

Please cite this article as: Brumme, S., Arnold, T., Sigmarsson, H., Lehmann, J., Scholz, H.C., Hardt, W.-D., Hensel, A., Truyen, U., Roesler, U., Impact of Salmonella Typhimurium DT104 Virulence Factors invC and sseD on the onset, clinical course, colonization patterns and immune response of porcine salmonellosis, Veterinary Microbiology (2007), doi:10.1016/j.vetmic.2007.04.032

This is a PDF file of an unedited manuscript that has been accepted for publication. As a service to our customers we are providing this early version of the manuscript. The manuscript will undergo copyediting, typesetting, and review of the resulting proof before it is published in its final form. Please note that during the production process errors may be discovered which could affect the content, and all legal disclaimers that apply to the journal pertain. 
1 IMPACT OF SALMONELLA TYPHIMURIUM DT104 VIRULENCE

2 FACTORS invC AND sseD ON THE ONSET, CLINICAL COURSE,

3 COLONIZATION PATTERNS AND IMMUNE RESPONSE OF PORCINE

4 SALMONELLOSIS.

5

6 Steffi Brumme ${ }^{\mathrm{a}, \mathrm{b}}$, Thorsten Arnold ${ }^{\mathrm{a}}$, Haukur Sigmarsson ${ }^{\mathrm{a}}$, Jörg Lehmann ${ }^{\mathrm{c}}$, Holger C.

7 Scholz ${ }^{\mathrm{a}, \mathrm{d}}$, Wolf-Dietrich Hardt ${ }^{\mathrm{e}}$, Andreas Hensel ${ }^{\mathrm{a}, \mathrm{f}}$, Uwe Truyen ${ }^{\mathrm{a}}$, and Uwe Roesler*, ${ }^{\text {a }}$ 8

9 a Institute of Animal Hygiene and Veterinary Public Health, University Leipzig, 10 Leipzig, Germany.

$11{ }^{\mathrm{b}}$ Impfstoffwerk Dessau-Tornau GmbH, Rodleben, Germany.

$12{ }^{\mathrm{c}}$ Fraunhofer Institute for Cell Therapy and Immunology, Leipzig, Germany.

$13{ }^{\mathrm{d}}$ Armed Forces Institute of Microbiology, Munich, Germany.

$14{ }^{\mathrm{e}}$ Institute of Microbiology, Swiss Federal Institute of Technology, Zürich, Switzerland.

$15 \quad{ }^{\mathrm{f}}$ Federal Institute for Risk Assessment, Berlin, Germany.

16

17

Running tit le: Impact of mutations of Salmonella inv C and sseD at pigs

20 * Correspon ding author:

21 Uwe Roesler

22 Institute of Animal Hygiene and Veterinary Public Health

23 An den Tierkliniken 1

2404103 Leipzig

25 Germany

26 Phone: +49 (0) 3419738153

27 Fax: +49(0) 3419738198

28 Email: roesler@vetmed.uni-leipzig.de 


\section{1}

\section{2}

3 The present study was conducted to study the impact of the virulence factors in $v C$ and $s s e D$ of

4 the two type III secretion systems of Salmonella enterica serovar Typhimurium

5 (S. Typhimurium) on the pathogenesis of the porcine $S$. Typhimurium DT104-infection. For

6 this purpose, two $S$. Typhimurium mutant strains with a disrupted $\operatorname{inv} C$ gene of the

7 Salmonella pathogenicity island 1 or with a disrupted sseD-gene of the Salmonella

8 pathogenicity island 2 have been studied in experimental infection of pigs.

9 Twenty two 7-week-old male hybrid pigs were either infected with one of the mutants or the 10 wild-type $S$. Typhimurium DT104 strain. Each group was examined for clinical signs, 11 Salmonella shedding rate and the specific antibody response. Survival and replication were 12 evaluated by qualitative and quantitative determination of the colonisation rate. The humoral and cellular immune responses were examined using isotype-specific ELISA and quantitative real-time PCR of IL-2, IL-4, IL-10, IL-12 and IFN- $\gamma$.

The results proved that both mutants had a lower virulence (with marked differences between both mutants) than the wild type and that both virulence factors have importance in porcine salmonellosis. Only pigs infected with the wildtype S. Typhimurium DT104 exhibited typical clinical symptoms of salmonellosis like anorexia, vomiting, disturbed demeanour, fever and diarrhoea. Deletion of the invC gene resulted in a significantly reduced colonisation rate. Interestingly, the mRNA expression of both type- 1 and type- 2 cytokines were significantly decreased in pigs infected with either the invC-mutant and the sseD-mutant strain.

KEYWORDS: Salmonella Typhimurium; invC; sseD; Salmonellosis; pig; swine; immune response; ELISA; Cytokines; Real time PCR 


\section{INTRODUCTION}

3

4 Salmonella enterica serovar Typhimurium (S. Typhimurium) is the most common Salmonella

5 serotype in pigs and a leading cause of food poisoning in humans. In Europe the prevalence of

6 S. Typhimurium phage type DT104 has steadily increased.

7 Salmonella enterica is a facultative intracellular bacterium capable of surviving within

8 phagosomes of macrophages and dendritic cells (Rathman et al. 1997). Previous studies

9 indicate that survival of $S$. Typhimurium within macrophages correlates with the virulence in

10 mice (Alpuche-Aranda et al. 1995). The most important virulence factors are encoded within

11 different Salmonella pathogenicity islands (SPI). SPI-1 is responsible for the membrane

12 ruffling, the invasion of epithelial cells and mediates intestinal pathogenesis (Galan 1999;

13 Barthel et al. 2003). SPI-1 mutants (e.g. sipB mutant) were shown to be significantly impaired

14 to invade the intestinal, but not the tonsillar tissue (Boyen et al. 2006). Furthermore, in-vitro

15 studies indicate that SPI-1 is responsible for apoptosis of macrophages, stimulation of

16 chloride secretion and the salmonellae induced Interleukin (IL)-8 production (Lundberg et al.

17 1999).

18 SPI-2 is required for survival and replication within the host cells, for systemic spread and for

19 en terocolitis (Bispham et al. 2001; Coombes et al. 2005; Hapfelmeier et al. 2005). Moreover,

20 SPI-2 seems to be responsible for the delayed apoptosis of macrophages with in the first 18-24

21 h of Salmonella infection (van der Velden et al. 2000; Monack et al. 2001). Some genes of

22 SPI-1 and SPI-2 encode two different highly conserved type III secretion systems (TTSS)

23 which translocate bacterial effector proteins into the host cell's cytosol to modulate signal

24 transduction pathways within host cells (Galan 1999). Two key components of these TTSS's

25 are inv $C$ and $s s e D$. The inv $C$ gene, a member of the invABC operon encodes a structural

26 component of the TTSS from SPI-1 with a significant ATPase activity. Thus, it is probably an 
1 energy provider for the TTSS (Eichelberg et al. 1994; Akeda \& Galan 2004). The sseD gene

2 encodes a putative translocon pore subunit of the surface-localized translocon module of the

3 SPI-2 that seems to be important for intracellular survival within macrophages (Nikolaus et al.

4 2001; Klein \& Jones 2001; Zurawski \& Stein 2003). In mice and calves invC and sseD

5 mutants of S. Typhimurüm were strongly attenuated indicating an important impact of these

6 two virulence factors (Bispham et al. 2001; Coombes et al. 2005; Hapfelmeier et al. 2005).

7 For efficient control of salmonellosis and for better understanding of Salmonella infections it

8 is essential to get more detailed information on the virulence factors of salmonellae and on the

9 specific cytokine response during a Salmonella infection. As the current knowledge of

10 salmonellosis and of Salmonella-induced immunity is predominantly based on experimental

11 infections of mice, further studies should focus on other natural hosts of S. Typhimurium, e.g.

12 pigs.

13 Therefore, the aim of the present study was to analyse the impact of two virulence factors,

14 invC and $s s e D$, of $S$. Typhimurium DT 104 in experimental porcine salmonellosis. Besides

15 analysing different clinical, microbiological and serological parameters, we also established

16 quantitative real-time PCR assays for the determination of interleukin-2, interleukin-4,

17 interleukin-10, interleuk in-12, and interferon- $\gamma$.

MATERIALS AND METHODS

Bacterial strains and culture conditions. A highly virulent, penta-resistant isolate of

S. Typhimurium DT 104 originally isolated from a clinically diseased pig was used as wild-

24 type strain. Both mutants, $S$. Typhimurium invC::aph T M 810 and the $S$. Typhimurium 25 sseD::aphT M 809 have been derived from this wild-type strain. 
1 All Salmonella strains were cultured in Luria Bertani (LB) broth to mid-log-arithmic growth

2 phase in an orbital incubator at $37^{\circ} \mathrm{C}$ and subsequently pelleted and washed once in PBS by

3 centrifugation (2000 x g for $10 \mathrm{~min}$ ). Bacteria were then counted and adjusted in ice-cold

4 phosphate buffered saline (PBS; pH 7.2) to a final cell number of $2 \times 10^{9} \mathrm{cfu} / \mathrm{ml}$.

5

6 Construction of invC::aphT and sseD::aphT deletion mutants. The deletion mutants of

$7 \quad$ invC and $s s e D$ were constructed as described by Eichelberg (1994). The SPI-1 and SPI-2

8 mutants were constructed by P22-transduction of the invC::aphT cassette from the Salmonella

9 strain SB566 (Eichelberg et al. 1994) or sseD::aphT from Salmonella strain MvP101 (Medina

10 et al. 1999), respectively.

12 Experimental design. Twenty-two 7-weeks-old male hybrid piglets (Landrace x Pietrain),

13 tested negative for Salmonella by faeces culture and ELISA (SALMOTYPE ${ }^{\circledR}$ Pig STM-WCE,

14 Labor Diagnostik Leipzig, Leipzig, Germany), were divided into three groups. The first group

15 ( $\mathrm{n}=6)$ was infected with the highly virulent wild-type strain $S$. Typhimurium DT104,

16 originating from a clinical case of salmonellosis, the second group $(n=8)$ and the third group

$17(\mathrm{n}=8)$ received the invC::aphT and the sseD::aphT mutant, respectively.

18 All groups were housed in air-conditioned high-security pens. Food and water were provided

19 ad libitum. The pigs of the three infection-groups were kept and handled separately. All

20 animal experiments were performed according to the German law of animal welfare

21 (Regierungspräsidium Leipzig; RN 24-9168.11).

22 After one week of adaptation the pigs were infected orally with the respective

23 S. Typhimurium DT104 strain. Feed was withdrawn $20 \mathrm{~h}$ before infection. Pigs were sedated

24 with $1 \mathrm{mg} / \mathrm{kg}$ i.m. Azaperon and fixed in a hammock in ventral position. Fifty millilitres of

25 bacterial suspension $\left(2 \times 10^{9} \mathrm{cfu} / \mathrm{ml}, 1 \times 10^{11}\right.$ salmonellae total inoculum per pig) were

26 administered via a gastric tube (Roesler et al. 2004). 
2 Clinical signs. Subsequent to infection, clinical signs including general demeanour,

3 respiration, coughing, vomiting, ingestion, diarrhoea and rectal body temperatures, were

4 monitored daily after infection for each pig. Clinical signs were graded into four levels with

$50=$ no symptoms, $1=$ mild symptoms, $2=$ medium symptoms and $3=$ severe symptoms.

6 Body weight was measured every third day for each pig.

7

8

9 Bacteriologic al examinations. After infection, the shedding rate of salmonellae in faeces of

10 each pig was determined daily for one week post infection. Later on, faecal samples were

11 collected and investigated every third day till day 21.

12 All pigs were euthanized by bleeding under anaesthesia at day 21 post infection (p.i.). Body

13 cavities were carefully opened to prevent contamination of internal organs by intestinal

14 content. The tissue samples were taken aseptically, using sterile instruments and bags.

15 Samples of $5 \mathrm{~g}$ from the quadriceps muscle, liver, spleen, lung, tonsils, ileum, jejunum, 16 caecum, colon, mandibular lymph node, lung (bronchial) lymph node, jejunal lymph node,

17 ileocolic lymph node, colic lymph node and bile fluid were collected for qualitative and 18 quantitative bacteriology. Each tissue sample was dipped in ethanol (95\%), flamed and

19 minced in a sterile bag. Then, peptone water $(45 \mathrm{ml})$ was added and each sample was 20 homogenized using a stomacher for $1 \mathrm{~min}$ at highest speed. The Stomacher bags with contents 21 were incubated for $24 \mathrm{~h}$ at $37^{\circ} \mathrm{C}, 100 \mu \mathrm{l}$ of the pre-enrichment suspensions were then added 22 to $9.9 \mathrm{ml} \mathrm{RV}$-bouillon and incubated for $24 \mathrm{~h}$ at $42{ }^{\circ} \mathrm{C}$ under aerobic conditions. Finally, the 23 enrichment broth was streaked in parallel onto XLD-plates and BPLS-plates and incubated for 24 further $24 \mathrm{~h}$ at $37^{\circ} \mathrm{C}$ under aerobic conditions. Colonies identified as Salmonella spp. were 25 further characterized by agglutination using polyclonal antisera (Sifin, Berlin Germany). 
1 For quantitative bacteriology, $25 \mu 1$ of the homogenized tissue suspension was used. A 10-

2 fold serial dilution in PBS was performed from each tissue in microtiter plates, and $25 \mu 1$ of

3 each dilution was transferred in triplicates on XLD and BPLS agar plates. All plates were 4 incubated for $24 \mathrm{~h}$ at $37^{\circ} \mathrm{C}$ under aerobic conditions.

5

6

7 Polymerase chain reaction. The $S$. Typhimurium isolates from the faeces and tis sue samples 8

were further characterized by a mutant-specific PCR. Primer sets for invC::aphT (5`-gcc ggc

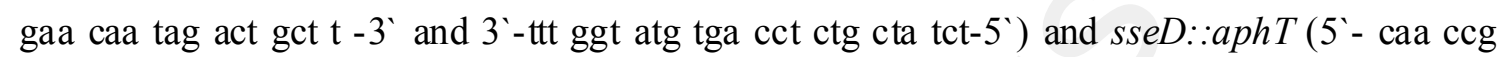
agg geg cca gtc aga $-3^{\prime}$ and $3^{`}-\mathrm{t}$ cag tcc aag taa geg ccc tat $-5^{\prime}$ ) yielded 2.5 and 1.8 kbase pairs. The amplification was performed in a thermocycler „Tpersonal“ (Biometra, Göttingen, Germany). The conditions for the PCR were an initial denaturation at $94{ }^{\circ} \mathrm{C}$ for $5 \mathrm{~min}$ followed by 35 cycles each of $40 \mathrm{~s}$ denaturation at $94{ }^{\circ} \mathrm{C}, 40 \mathrm{~s}$ annealing at $60{ }^{\circ} \mathrm{C}$, and $90 \mathrm{~s}$ extension at $72{ }^{\circ} \mathrm{C}$ and a final extension step of $5 \mathrm{~min}$ at $72{ }^{\circ} \mathrm{C}$. Ten microlitres of each PCR product were separated on a $2 \%$ agarose gel in TAE buffer (40 mM Tris, $20 \mathrm{mM}$ acetic acid, and $1 \mathrm{mM}$ EDTA) by electrophoresis. Amplicons were stained with ethidium bromide $(0.5 \mathrm{~g} / \mathrm{ml})$ visualized with the Bio-Rad Gel Doc 2000 imager system (Bio-Rad, München, Germany).

Serological examinations. The isotype-specific systemic antibody response was evaluated using the "SALMOTYPE ${ }^{\circledR}$ Pig STM-WCE ELISA (Labor Diagnostik Leipzig). All incubations and washing steps were done as described by the supplier. Antibody activities were expressed as ELISA units per $\mathrm{ml}(\mathrm{EU} / \mathrm{ml})$ using the positive-reference-standard method (Wright et al. 1993). The enzymatic reactions were developed with a TMB-based chromogen and measured by a computer-controlled photometer at $450 \mathrm{~nm}$ (Multiscan Ascent ${ }^{\circledR}$, Thermo 
1 Electron, McLean, USA). The data were analysed using the software Salmosoft ${ }^{\mathrm{TM}}$ (Labor

2 Diagnostik Leipzig).

3

4 Cytokine quantification. EDTA blood samples were taken at day 0, 7, 14, and 21 after

5 infection. The mononucleated cells were purified by density gradient centrifugation with

6 Bicoll $^{\circledR}$ Separating Solution (Biochrom, Berlin, Germany) and subsequently, RNA was

7 extracted by a silica-based procedure according to the manufacturer's instructions (Qiagen

8 RNeasy $\mathrm{Kit}^{\mathrm{TM}}$; Qiagen, Hilden, Germany). First strand cDNA was synthesized using the Taq ${ }^{\circledR}$

9 Reverse Transcription Reagents (Applied Biosystems, Weiterstadt, Germany) with random

10 hexamer oligonucleotides.

11 For relative quantification of the respective cytokine cDNA we developed duplex real-time

12 PCR assays. To normalize the results of the cytokine quantification the housekeep ing gene for 13 glyceraldehydes-3-phosphate dehydrogenase (GAPDH) was used. Primers and probes 14 (Table 1) for pig IL-2, IL-4, IL-10, IL-12, IFN- $\gamma$ and GAPDH were provided by biomers Ltd.

15 (biomers.net, Ulm, Germany). The probes were dually labelled with a reporter dye (HEX for 16 the targets or FAM for GAPDH) at the 5 end and the black hole quencher 1 (BHQ 1) at the 173 end. All templates were examined in triplicates and no-template controls (NTC) were 18 additionally included.

19 The PCRs were performed on a MX $3000 \mathrm{P}^{\circledR}$ thermal cycler (Stratagene, West Cedar Creek, 20 USA) by means of TaqMan ${ }^{\circledR}$-probes. The ex vivo real-time amplification for the cytokine 21 quantification of IL-2, IL-4, IL-10, IL-12 and IFN- $\gamma$ was carried out in a total volume of $25 \mu 1$ 22 in triplicates. The two-step PCR reactions were cycled 42-times after initial denaturation $23\left(95^{\circ} \mathrm{C}, 15 \mathrm{~min}\right)$ with the following parameters: denaturation at $95^{\circ} \mathrm{C}$ for $30 \mathrm{~s}$ and annealing 24 (and extension) at $58^{\circ} \mathrm{C}$ for $1 \mathrm{~min}$.

25 The real-time PCR efficiencies of the duplex PCRs (target gene and GAPDH) were 26 determined for each primer/probe set from standard curves generated from serial dilution s of a 
1 cDNAs. The resulting standard curves always revealed linearity and efficiencies of $96.3 \%$ for

2 IFN- $\gamma, 92.4 \%$ for IL-2, $92.3 \%$ for IL-4, $94.2 \%$ for IL- 10 and $96.8 \%$ for IL- 12.

3 The results of the PCR were calculated by the comparative $\mathrm{C}_{\mathrm{T}}$ method (Pfaffl 2001) for

4 relative quantification ( software MxPro-Mx3000 ${ }^{\mathrm{TM}}$, Stratagene). The relative expression level

5 is compared with a calibrator, in this study non-treated samples of the pigs taken before

6 experimental infection. The target amount, normalized to the endogenous housekeep ing gene

7 (GAPDH) and relative to the calibrator, is then calculated by the formula: $2^{-\Delta \Delta C T}$.

9 Statistical analyses. The results of the serological investigation, the bacteriological 10 quantitative examination and the ex vivo quantitative real-time PCR were calculated and 11 plotted as notch boxes. The median (internal horizontal line), upper and lower quartiles (the 12 upper and lower horizontal margins of the boxes), the $95 \%$ confidence limits (the oblique margins of the boxes) and the extreme values are shown (McGill et al. 1978). Significant

14 differences were tested by Mann-Whitney $\mathrm{U}$ test. A $p$ value of $\leq 0.05$ was considered 15 significant. The results of the qualitative bacteriological investigation and of the clinical 16 examination were tested by the $\chi^{2}$ test. $p$ values of $\leq 0.05$ were considered significant.

RESULTS

21 Clinical signs. After challenge infection with the respective $S$. Typhimurium DT104 strain only the pigs infected with the wild-type $S$. Typhimurium showed typical clinical symptoms of salmonellosis, such as anorexia, vomiting, disturbed demeanour, fever and diarrhoea. Two pigs of the wild-type group died at day 2 after infection with high-grade signs of salmonellosis (diarrhoea, dehydration, fever). All challenged pigs showed a disturbed 26 demeanour on the first day after infection. The rectal temperature differed significantly 
$1 \quad(p \leq 0.05)$ between the wild-type group and both mutant groups. The pigs of the wild-type

2 group showed 1 to 4 days after infection a markedly elevated rectal temperature $\left(39.9^{\circ} \mathrm{C}\right.$ -

$341.3^{\circ} \mathrm{C}$, mean $40.4{ }^{\circ} \mathrm{C}$ on $1^{\text {st }}$ day after infection), whereas the rectal temperatures of both

4 mutant groups were at normal levels.

5 Furthermore, all animals of the wild-type infected group had clearly diminished faeces

6 consistency. At day 2 post infection all animals of the wild type group showed severe

7 diarrhoea (score 2-3). Starting at day 7 post infection this diarrhoea became intermittent and

817 days post infection the faecal consistency was back to normal. In summary, pigs infected

9 with wild-type $S$. Typhimurium DT104 showed a significantly higher mean of the clinical

10 score $(p \leq 0.05)$, which peaked at day 4 post infection (Figure 1$).$

12 Bacteriological examinations. S. Typhimurium DT104 was not isolated from any

13 investigated faecal samples before challenge, whereas all infected pigs shed the respective

$14 S$. Typhimurium strain after challenge infection. The animals of the wild-type group were

15 continuous shedders ( $100 \%)$ during the complete observation period. In contrast, all pigs of

16 the mutant groups were intermittent shedders. The pigs infected with the invC::aphT mutant,

17 shed S. Typhimurium DT104 from the $3^{\text {rd }}$ day p.i. till the end of the observation period with

18 rates between 55.6 and $100 \%$. The animals of the $s s e D:: a p h T$ infection group shed their

19 challenge strain with faeces from day 3 till day 14 p.i. with a rate of $100 \%$, but subsequently

20 they became intermittent shedders $(75 \%-87.5 \%)$ (Figure 2).

21 The qualitative bacteriological examination of 15 tissue samples of each pig was done with

22 special regard to organs and tissues, which are directly used in food production (i.e. lung,

23 liver, spleen and muscles) or which have immunological relevance (tonsil, mandibular lymph

24 node, lung lymph node, spleen, jejunal lymph node, ileocolic lymph node and colic lymph 25 node). 
1 Each animal of the wild-type infected group was Salmonella-positive in tonsils, caecum,

2 mandibular lymph node, lung lymph node, jejunal lymph node and ileocolic lymph node

3 (Figure 3). However, the wild-type challenge strain could not be isolated from liver and bile.

4 The qualitative bacteriological examination of the tissue samples of the invC::aphT mutant 5 group showed markedly decreased colonization rates (at day 21 p.i.) in organs with 6 importance for food production (i.e. lung, liver, spleen and muscles). The invC::aphT mutant

7 strain could not be detected in samples derived from liver, spleen, or bile. The majority of 8 invC::aphT mutant group had Salmonella-positive tonsils, mandibular lymphnodes, and 9 GALT.

10 In contrast, the examination of the sseD::aphT mutant group showed a colonization rate of $11100 \%$ in tonsils, ileum, colon, caecum, mandibular lymph node, ileocecal lymph node and 12 colic lymph node. Altogether, the $s s e D$ mutant infected group showed virtually the same 13 colonization rates as the wild-type infected pigs.

14 Every positive detection of Salmonella could be confirmed with the strain specific (wild-type 15 or both mutants) qualitative PCR.

16 The quantitative Salmonella detection showed markedly decreased Salmonella counts in some 17 tissues in the inv $C: \because$ aphT, whereas the sseD mutant infected group showed similar or even 18 significantly higher (in jejunal lymph nodes and ileocolic lymph nodes) quantities of 19 salmonellas in the organs as the wild-type infected pigs (Figure 4).

21 Serological examinations. Salmonella-specific antibody activities in serum were measured 22 by the reference standard ELISA SALMOTYPE ${ }^{\circledR}$ Pig STM-WCE (Labor Diagnostik 23 Leipzig). Thereby, isotype-specific antibody activities were determined during the 24 observation period of 21 days p.i.. Thereby, the attenuation of the strains interfered with the 25 humoral immune responses of the respective groups (Figure 5). 
1 In comparison to the pigs of the mutant groups, the pigs of the wild-type group showed

2 significantly higher antibody activities in serum.

3

4 Relative cytokine expression rate of the wild type infection group. All investigated 5 cytokines (IL-2, IL-4, IL-10, IL-12, and IFN- $\gamma$ ) showed similar kinetics (Figures 6 and 7). The 6 ex-vivo expression rate of all investigated cytokines decreased in the first days after infection.

7 However, afterwards there was a significant increase (20-fold) of mRNA expression of all 8 investigated cytokines, with exception of IL-10 which only reached the initial value. During 9 the following observation period a further strong increase was seen in case of IL-2 (440-fold), 10 IL-4 (650-fold), IL-12 (460-fold) and IFN $\gamma$ (83-fold), while only a 2-fold increase of IL-10 11 mRNA expression was detectable.

12 Relative cytokine expression rate of the invC::aphT mutant group. At the beginning of the 13 observation period there was a suppression of the relative expression rate of IL-2, IL-12 and 14 IFN $\gamma$. Later, all measured cytokines were found to be induced, but however, at a significantly 15 lower level in comparison to the wild-type group. The highest mRNA expression rate was 16 found for IFN- $\gamma$.

18 Relative cytokine expression rate of the sseD::aphT mutant group. In this group the 19 expression rates of IL-2 and IL-4 were also decreased at the beginning of the experimental 20 Salmonella infection. The most significant suppression was found for IL-2 and IL-4 with a 21 decrease of $87 \%$ each. IL-12, IL-10 and IFN $\gamma$ were only slightly depressed during the first 22 days of infection. Later, the mRNA expression of all cytokines was significantly lower with 23 the sharp est decline for IL-10 (490 fold). 
1 Altogether, the comparative investigation of the cytokine mRNA expression between pigs

2 infected with the wild-type strain of $S$. Typhimurium DT104 and invC- or sseD-mutants

3 showed, that the cellular immune response against both mutants is in general reduced.

4

5

6 DISCUSSION

7

8 Knowled ge about pathogen esis (e.g. adhesion, invasion, and survival and replication in hosts)

9 is needed for effective measures to control salmonellosis. The present study demonstrates the impact of the two components invC and $s s e \mathrm{D}$ of the two type III secretion systems of Salmonella on porcine salmonellosis.

Loss of virulence could be demonstrated with both deletion mutants of $S$. Typhimurium DT104 in the important reservoir pig. As before shown in the mouse model, lower clinical symptoms were shown by the pigs of both mutant groups (Coombes et al. 2005; Hapfelmeier et al. 2005). Only pigs infected with the wild-type strain showed typical clinical signs of salmonellosis. The pigs of both groups infected with one of the mutants shed the pathogen intermittently, whereas the pigs infected with the wild type shed S. Typhimurium DT104 bacteria continuously. Thereby, the invC mutant displayed the lowest shedding rate. Impaired invasion could explain this phenomenon.

To further analyse the impact of the two components inv $C$ and sseD of the Salmonella type III secretion systems the ability for invasion and colonization was also examined. $S$. Typhimurium is an invasive pathogen with the ability of systemic spread via the bloodstream and the lymphatic system. Thus, Salmonella are often detected in tonsils, jejunum, ileum, caecum, colon, and mandibular- and ileocolic lymph nodes. Presumably, these organs influence the persistence of Salmonella (Wood et al. 1989). However, a link 
1 between inoculation route and colonisation rate could not be found (Fedorka-Cray et al. 2 1995).

3 In this study, significant differences were shown between the $S$. Typhimurium DT104 wild 4 type strain and both mutants. Previous in-vitro studies with an invC mutant of Salmonella 5 enterica demonstrated a loss of the ability to invade epithelial cells (Gallo is et al. 2001). Here, 6 we could confirm these former findings also in swine, because the colonisation rate of inner 7 organs was signific antly reduced in the invC mutant group. In contrast, the sseD::aphT mutant 8 group was colonized in average at $69.2 \%$ and the wild-type group on average at $68.3 \%$ of the 9 organs examined. Salmonella were detectable in mandibular lymph nodes of pigs of all three 10 groups. We also found high colonization levels of the wild-type and mutant strains in tonsils, 11 ileum, colic, caecum, jejunal lymph node, ileocolic lymph nodes and colic lymph nodes 12 indicating the ability of both mutant strains to leave the gut system and to invade the 13 mesenteric lymph nodes. However, the significantly reduced colonisation rate in organs 14 outside of the GALT demonstrates the impact of the invC gene in the process of invasion. 15 This is in line with the findings of Boyen (2006) which showed that another SPI-1 mutant, 16 namely of sipB, was also significantly impaired to invade the porcine gut.

17 In contrast, the quantitative bacteriological examination of the tissue samples with 18 significantly higher counts of salmonellae in jejunic lymph nodes and ileocolic lymph nodes 19 show a lack of attenuation of the sseD::aphT mutant compared to the wild-type bacteria. 20 These results contradict former results from experimental infections in mice (Coombes et al. 21 2005; Hapfelmeier et al. 2005).

22 The results of specific serum antibody measurement indicate a significantly decreased 23 antibody response of both mutant groups. This fact is closely associated with a significantly 24 lower ex-vivo mRNA expression rate of IL-4 in pigs of both mutant groups. IL-4 acts as the 25 most important differentiation cytokine for the Th2-pathway and thereby, suppresses Th1 26 activity and additionally it stimulates clonal proliferation of B cells. It is commonly accepted, 
1 that antibody response is less important than cell-mediated immune mechanisms during

2 infection with Salmonella. On the other hand, the humoral immune response seems to be

3 necessary for the protection against a secondary infection with salmonellae (Mittrucker et al.

4 2000). Furthermore, systemic antibodies eliminate salmonellae from the blood and promote

5 phagocytosis of salmonellae by opsonization (Mastroeni et al. 2001). It was already shown in

6 mice, that B cells and their specific antibodies are not essential during a primary or secondary

7 infection with attenuated salmonellae. However, antibodies accelerate healing. In addition,

8 there is a correlation between the existence of specific antibodies and vaccine-induced

9 resistance (McSorley \& Jenkins 2000). Moreover, IL-4-dependent immune mechan isms seem

10 to be indispensable for sterile elimination of attenuated salmonellae as shown in mice

11 (Lehmann et al. 2006).

12 Salmonellae are facultative intracellular pathogens, which can stimulate both pathways of the

13 immune system, the cellular and the humoral. The Th1 response starts within few hours post

14 infection resulting in elimination of salmonellae and protection against re-infection

15 (Mittrucker et al. 2000).

16 The concerted action of sev eral cytok ines including TNF- $\alpha$, IFN- $\gamma$, IL- 12 , and IL- 18 is needed

17 for the suppression of bacterial growth in the plateau phase of a Salmonella infection. IL-12

18 mediates resistance to several intracellular organisms and it is essentially required for the

19 establishment of the protective Th1 response (Lehmann et al. 2001). This interleuk in induces

20 IFN- $\gamma$ in natural killer (NK) cells and presents a co-stimulus required for maximum IFN- $\gamma-$

21 and IL-2-secretion by antigen-activated Th1 cells. The resulting Th1 response promotes

22 primary cellular immunity, whereas Th2 cells produce IL-4 and IL-10 resulting mainly in

23 humoral immunity. Our data show an eminently higher IL-12 expression rate in pigs of the

24 Salmonella wild-type group. Additionally, the increase of IFN- $\gamma$ and IL-2 was also

25 significantly higher in the wild-type group. IFN- $\gamma$ stimulates activation of macrophages and

26 promotes the killing of Salmonella within macrophages. The markedly decreased IFN- $\gamma$ 
1 mRNA expression of the invC::aphT mutant group probably results from the reduced ability

2 of invasion and therefore, the lower cell damage. Other studies showed such a correlation

3 between low level of IFN- $\gamma$ and cell damage (Trebichavsky et al. 2003). Altogether, the

4 detected increased expression rates of IL-2, IL-12, and IFN- $\gamma$ in the Salmonella wild-type

5 group are in accordance with the results of other studies in animals and humans (Bao et al.

6 2000) and are most probably associated with a protective immune response against

$7 \quad$ Salmonella.

8 IL-10 is one of the most potent anti-inflammatory cytokines. This interleukin inhibits the 9 antigen presentation to $\mathrm{T}$ cells and suppresses phagocytosis and intracellular killing 10 (Fiorentino et al. 1991). This effect is mediated by the down-regulation of the class II MHC 11 and co-stimulatory molecules. Furthermore, IL-10 inhibits the production of reactive oxygen 12 intermediates (ROI) and reactive nitrogen intermediates (RNI) in activated macrophages. On 13 the other hand, macrophages are a major source of IL-10 production. We could show that both 14 mutants had the same potency to stimulate IL-10 production as the S. Typhimurium DT104 15 wild-type strain in the first days of infection. There is an interesting involvement of the 16 factors of SPI-2 in a signal transduction pathway that induces cytokine expression in 17 Salmonella infected macrophages. Thereby, Salmonella and some other intracellular 18 pathogens use IL-10 to survive within macrophages or to inhibit the host defence (Uchiya et 19 al. 2004). The role of the SPI-2 encoded secretion system is to interfere with intracellular 20 vesicular trafficking to avoid exposure to toxic agents such as ROI and RNI in infected 21 macrophages (Chakravortty et al. 2002). Compared to the wild-type group, our data show 22 high IL-10 expression rates of the sseD mutant group (as high as at the wildtype group) in the 23 first days of infection. We could therefore assume that the loss of sseD did not result in a 24 disability to avoid exposure to toxic agents in the macrophages. This assumption is supported 25 by the high colonization rates in pigs of the $s s e D$ mutant group. Therefore, our data indicate 26 that the loss of the sseD gene of SPI-2 did not result in a decreased survival in porcine 
1 macrophages, which is in contrast to the results obtained in mice (Hapfelmeier et al. 2005).

2 Finally, further studies with ROI and RNI measurements at macrophages infected with the

3 used sseD-mutant should answer this question.

4 In general, we noted an immunosuppressive effect in all infection groups at the beginning of

5 the observation period. A possible reason is the high challenge dose to show possible

6 differences in shedding of salmonellae and in clinical symptoms of salmonellosis. Previously,

7 this immunosuppressive effect has been described in chicken (Hassan \& Curtiss 1994). The

8 lymphocyte depletion and immunosuppression might play a critical role in the development of

9 the Salmonella carrier status. Furthermore, a significant lower expression of IFN- $\gamma$ was

10 observed in susceptible infected chicken in comparison to resistant animals. The reduced

11 expression rate of IFN- $\gamma$ can be a valuable indication of immunodeficiency associated with

12 persistence of Salmonella in the chicken's digestive tract (Sadeyen et al. 2004).

13 Altogether, we could show, that the virulent wild-type strain of S. Typhimurium DT104

14 possesses a significantly higher potency to stimulate the cytokine response in porcine immune

15 cells compared to both mutants with deletions in the two Salmonella type III secretion

16 systems. Thereby, the mildest reactions were noticed in animals of the invC::aphT mutant

17 group; which is in line with the disability of invasion.

18 In summary, this study shows that the invC::aphT and sseD::aphT mutants of S. Typhimurium

19 DT104 posses a significant reduced virulence in swine. Thereby, the invC deletion results in

20 more evident attenuation than the $s s e D$ deletion, because of a total loss of clinical signs of

21 salmonellosis and significantly reduced colonisation rates. The sseD deletion mutant,

22 however, was not able to induce clinical symptoms of porcine salmonellosis and induced

23 lower cellular and humoral immunity, but the colonization rates of the tested tissues were in

24 parts significantly higher compared to the wild-type. 


\section{ACKNOWLEDGMENTS}

4

The technical ass is tance of Eveline Brumme and Nadja Leinecker is gratefully acknowledged.

\section{REFERENCES}

Akeda, Y., Galan, J.E., 2004. Genetic analysis of the Salmonella enterica type III secretionassociated ATPase InvC defines discrete functional domains. J. Bacteriol., 186, 2402-2412.

Alpuche-Aranda, C.M., Berthiaume, E.P., Mock, B., Swanson, J.A., Miller, S.I., 1995. Spacious phago some formation within mouse macrophages correlates with Salmonella serotype pathogenicity and host susceptibility. Infect. Immun., 63, 4456-4462.

Bao, S., Beagley, K.W., France, M.P., Shen, J., Husband, A.J., 2000. Interferon-gamma plays a critical role in intestinal immunity against Salmonella typhimurium infection. Immunology, 99, 464-472.

Barthel, M., Hapfelmeier, S., Quintanilla-Martinez, L., Kremer, M., Rohde, M., Hogardt, M., Pfeffer, K., Russmann, H., Hardt, W.D., 2003. Pretreatment of mice with streptomycin provides a Salmonella enterica serovar Typhimurium colitis model that allows analysis of both pathogen and host. Infect. Immun., 71, 2839-2858.

Bispham, J., Tripathi, B.N., Watson, P.R., Wallis, T.S., 2001. Salmonella pathogenicity island 2 influences both systemic salmonellosis and Salmonella-induced enteritis in calves. Infect. Immun., 69, 367-377.

Chakravortty, D., Hansen-Wester, I., Hensel, M., 2002. Salmonella pathogenicity island 2 mediates protection of intracellular Salmonella from reactive nitrogen intermediates. J. Exp. Med., 195, 1155-1166.

Coombes, B.K., Coburn, B.A., Potter, A.A., Gomis, S., Mirakhur, K., Li, Y., Finlay, B.B., 2005. Analysis of the contribution of Salmonella pathogenicity islands 1 and 2 to enteric disease progression using a novel bovine ileal loop model and a murine model of infectious en terocolitis. Infect. Immun., 73, 7161-7169.

Eichelberg, K., Ginocchio, C.C., Galan, J.E., 1994. Molecular and functional characterization of the Salmonella typhimurium invasion genes in $v B$ and invC: homology of InvC to the F0F1 ATPase family of proteins. J. Bacteriol., 176, 4501-4510.

Fedorka-Cray, P.J., Kelley, L.C., Stabel, T.J., Gray, J.T., Laufer, J.A., 1995. Alternate routes of invasion may affect pathogenesis of Salmonella typhimurium in swine. Infect. Immun., 63, 2658-2664.

Fiorentino, D.F., Zlotnik, A., Mosmann, T.R., Howard, M., Ogarra, A., 1991. IL-10 inhibits cytokine production by activated macrophages. J. Immunol., 147, 3815-3822. 
1 Galan, J.E., 1999. Interaction of Salmonella with host cells through the centisome 63 type III

2 secretion system. Curr. Opin. Microbiol., 2, 46-50.

3 Gallois, A., Klein, J.R., Allen, L.A., Jones, B.D., Nauseef, W.M., 2001. Salmonella

4 pathogenicity island 2-encoded type III secretion system mediates exclusion of NADPH

5 oxidase assembly from the phagosomal membrane. J. Immunol., 166, 5741-5748.

6 Hapfelmeier, S., Stecher, B., Barthel, M., Kremer, M., Müller, A.J., Heikenwalder, M.,

7 Stallmach, T., Hensel, M., Pfeffer, K., Akira, S., Hardt, W.D., 2005. The Salmonella

8 pathogen icity island (SPI)-2 and SPI-1 type III secretion systems allow Salmonella serovar

9 typhimurium to trigger colitis via MyD88-dependent and MyD88-independent mechanisms. J.

10 Immunol., 174, 1675-1685.

11 Hassan, J.O., Curtiss,R.III, 1994. Virulent Salmonella typh imurium-induced lymphocyte

12 depletion and immunosuppression in chickens. Infect. Immun., 62, 2027-2036.

Klein, J.R., Jones, B.D., 2001. Salmonella pathogenicity island 2-encoded proteins SseC and SseD are essential for virulence and are substrates of the type III secretion system. Infect. Immun., 69, 737-743.

Lehmann, J., Bellmann, S., Werner, C., Schröder, R., Schutze, N., Alber, G., 2001. IL-12p40dependent agonistic effects on the development of protective innate and adaptive immunity against Salmonella enteritidis. J. Immunol., 167, 5304-5315.

Lehmann, J., Springer, S., Werner, C.E., Lindner, T., Bellmann, S., Straubinger, R.K., Selbitz, H.J., Alber, G., 2006. Immunity induced with a Salmonella enterica serovar Enteritidis live vaccine is regulated by Th1-cell-dependent cellular and humoral effector mechanisms in susceptible BALB/c mice. Vaccine, 24, 4779-4793.

Lundberg, U., Vinatzer, U., Berdnik, D., von Gabain, A., Baccarini, M., 1999. Growth phaseregulated induction of Salmonella-induced macrophage apoptosis correlates with transient expression of SPI-1 genes. J. Bacteriol., 181, 3433-3437.

Mastroeni, P., Chabalgo ity, J.A., Dunstan, S.J., Maskell, D.J., Dougan, G., 2001. Salmonella: immune responses and vaccines. Vet. J., 161, 132-164.

McGill, R.J., Tukey, J.W., Larson, W.A., 1978. Variations of Box Plots. Am. Statist., 32, 1216.

McSorley, S.J., Jenkins, M.K., 2000. Antibody is required for protection against virulent but not attenuated Salmonella enterica serovar typhimurium. Infect. Immun., 68, 3344-3348.

Medina, E., Paglia, P., Nikolaus, T., Müller, A., Hensel, M., Guzman, C.A., 1999. Pathogenicity island 2 mutants of Salmonella typhimurium are efficient carriers for heterologous antigens and enable modulation of immune responses. Infect. Immun., 67, 10931099 .

Mittrucker, H.W., Raupach, B., Kohler, A., Kaufmann, S.H., 2000. Cutting edge: role of B lymphocytes in protective immunity against Salmonella typh imurium infection. J. Immunol., 164, 1648-1652. 
1 Monack, D.M., Detweiler, C.S., Falkow, S., 2001. Salmonella pathogenicity island 2-

2 dependent macrophage death is mediated in part by the host cysteine protease caspase- 1 . Cell

3 Microbiol., 3, 825-837.

4 Nikolaus, T., Deiwick, J., Rappl, C., Freeman, J.A., Schröder, W., Miller, S.I., Hensel, M.,

5 2001. SseBCD proteins are secreted by the type III secretion system of Salmonella

6 pathogen icity island 2 and function as a translocon. J. Bacteriol., 183, 6036-6045.

7 Pfaffl, M.W., 2001. A new mathematical model for relative quantification in real time RT-

8 PCR. Nucleic Acids Res., 29, e45.

9 Rathman, M., Barker, L.P., Falkow, S., 1997. The unique trafficking pattern of Salmonella

10 typhimurium-containing phagosomes in murine macrophages is ind ependent of the

11 mechanism of bacterial entry. Infect. Immun., 65, 1475-1485.

12 Roesler, U., Marg, H., Schröder, I., Mauer, S., Arnold, T., Lehmann, J., Truyen, U., Hensel, A., 2004. Oral vaccination of pigs with an invasive gyrA-cpxA-rpoB Salmonella

14 Typhimurium mutant. Vaccine, 23, 595-603.

Sadeyen, J.R., Trotereau, J., Velge, P., Marly, J., Beaumont, C., Barrow, P.A., Bumstead, N., Lalmanach, A.C., 2004. Salmonella carrier state in chicken: comparison of expression of immune response genes between susceptible and resistant animals. Microbes. Infect., 6, 1278181286.

Trebichavsky, I., Splichal, I., Splichalova, A., Muneta, Y., Mori, Y., 2003. Systemic and local cytokine response of young piglets to oral infection with Salmonella enterica serotype Typhimurium. Folia Microbiol. (Praha), 48, 403-407.

Uchiya, K., Groisman, E.A., Nikai, T., 2004. Involvement of Salmonella pathogenicity is land 2 in the up-regulation of interleukin-10 expression in macrophages: role of protein kinase $\mathrm{A}$ signal pathway. Infect. Immun., 72, 1964-1973.

van der Velden, A.W., Lindgren, S.W., Worley, M.J., Heffron, F., 2000. Salmonella pathogenicity island 1-independent induction of apoptosis in infected macrophages by Salmonella enterica serotype typh imurium. Infect. Immun., 68, 5702-5709.

Wood, R.L., Pospischil, A., Rose, R. 1989. Dis tribution of persistent Salmonella typhimurium infection in in ternal organs of swine. Am. J. Vet. Res., 50, 1015-1021.

Wright, P.F., Nilson, E., Van Rooij, E.M.A., Lelenta, M., Jeggo, M.H., 1993. Standardisation and validation of enzyme-linked-immunosorbent assay techniques for the detection of antibody in infectious disease diagnosis. Rev. sci. tech. Off. int. Epiz., 12, 435-450. Salmonella Pathogenicity Island 2 translocon. Mol. Microbiol., 47, 1341-1351. 
1

\section{2}

3 FIG. 1. Mean clinical score (general demeanour, vomiting, anorexia and diarrhoea) of pigs of

4 the $S$. Typhimurium DT104 wild-type group (filled circle), of animals of the invC::aphT

5 mutant group (circles), and of pigs of the sseD: :aphT mutant group (filled triangles). Clinical

6 signs were quantified using a clinical score: $0=$ no symptoms, $1=$ mild symptoms,

$7 \quad 2$ = medium symptoms, and $3=$ severe symptoms. (\#) indicates significant differences

$8 \quad(p<0.05)$ between wild type group and mutant groups.

9

FIG. 2. Shedding rate of $S$. Typhimurium DT104 (wildtype and two mutants) in faeces of experimentally infected pigs. The black bars represent the pigs infected with the $S$. Typhimurium DT104 wild-type, the white bars the pigs infected with the invC::aphT mutant, and the grey bars the animals infected with the sseD::aphT mutant.

FIG. 3. Colonization rate of $S$. Typhimurium DT104 (wildtype and two mutants) in tissue samples after qualitative bacterial examination. The black bars represent the pigs infected with the $S$. Typhimurium DT104 wild-type, the white bars the pigs infected with the invC::aphT mutant, and the grey bars the animals infected with the sseD::aphT mutant. Significant differences $(p \leq 0.05)$ between the wild-type group and the mutant groups are indicated by asterisks (*) and between both mutant groups by \#. MaLn, mandibular lymphnode; JeLn, jejunal lymphnode; IcLn, ileocolic lymphnode; colic lymphnode.

FIG. 4. Colonization rate of $S$. Typhimurium DT104 in tissue samples after quantative bacterial examination. The black notch boxes represent the pigs infected with the S. Typhimurium DT104 wild-type, the white notch boxes the pigs infected with the invC::aphT mutant, and the grey notch boxes the animals infected with the sseD::aphT 
1 mutant. Significant differences $(p \leq 0.05)$ between the wild-type group and the mutant groups

2 are indicated by asterisks $(*)$ and between both mutant groups by the \# sign. MaLn, 3 mandibular lymphnode; JeLn, jejunal lymphnode; IcLn, ileocolic lymphnode; colic 4 lymphnode.

5

6 FIG. 5. Salmonella specific IgM antibody activities in serum of pigs experimentally infected 7 with the $S$. Typhimurium DT104 wild type strain (black bars), invC::aphT mutant strain 8 (white bars) and sseD::aphT mutant strain (grey bars). Significant differences $(p \leq 0.05)$ 9 between the wild-type group and the mutant groups are indicated by asterisks (*) and 10 significant differences between both mutant groups by the \# sign.

FIG. 6. Relative ex-vivo mRNA expression rates of IL-2 (A), IL-4 (B) and IL-10 (C) after experimental infection with $S$. Typhimurium DT 104 in animals of the wild-type group (black notch boxes), the invC::aphT mutant group (white notch boxes), and the sseD::aphT mutant group (grey notch boxes). Asterisks $\left(^{*}\right)$ indicate significant differences $(p<0.05)$ between 16 wild-type group and the respective mutant group.

FIG. 7. Relative ex-vivo mRNA expression rates of IL-12 (A) and Gamma-Interferon (B) after experimental infection with $S$. Typhimurium DT 104 in animals of the wild-type group (black notch boxes), the invC::aphT mutant group (white notch boxes), and the sseD::aphT mutant

21 group (grey notch boxes). Asterisks $(*)$ indicate significant differences $(p<0.05)$ between 22 wild-type group and the respective mutant group. 


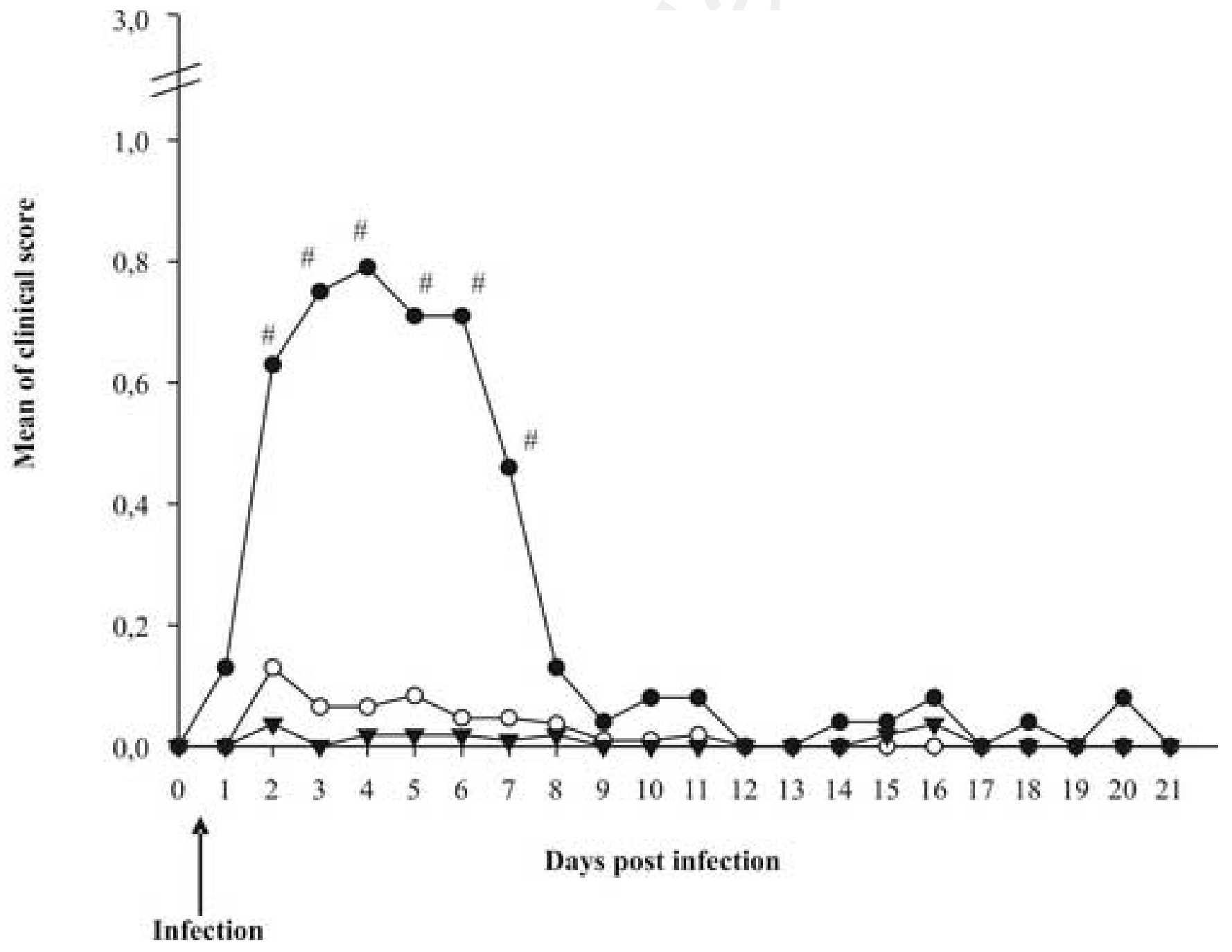

Page 23 of 30 


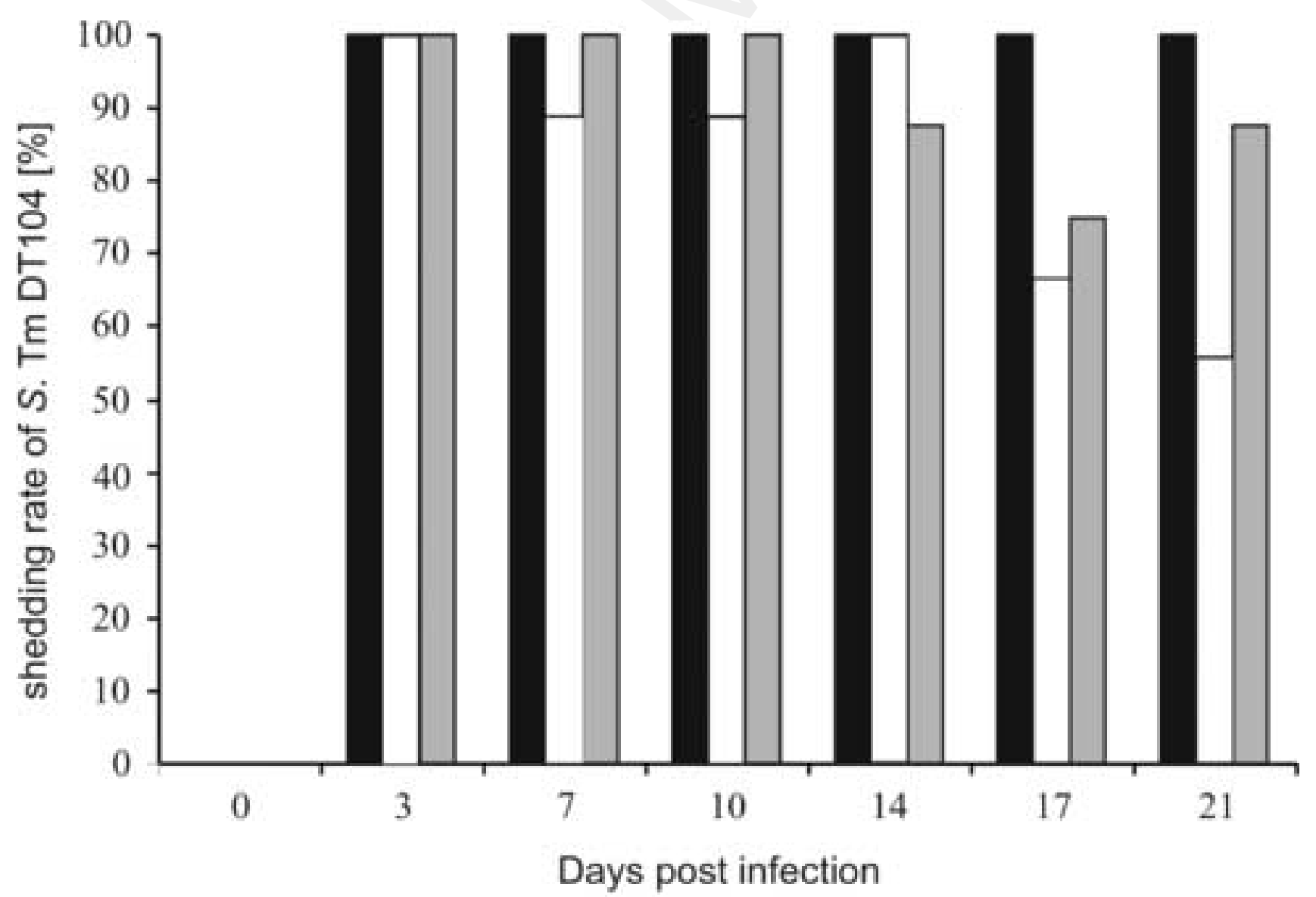




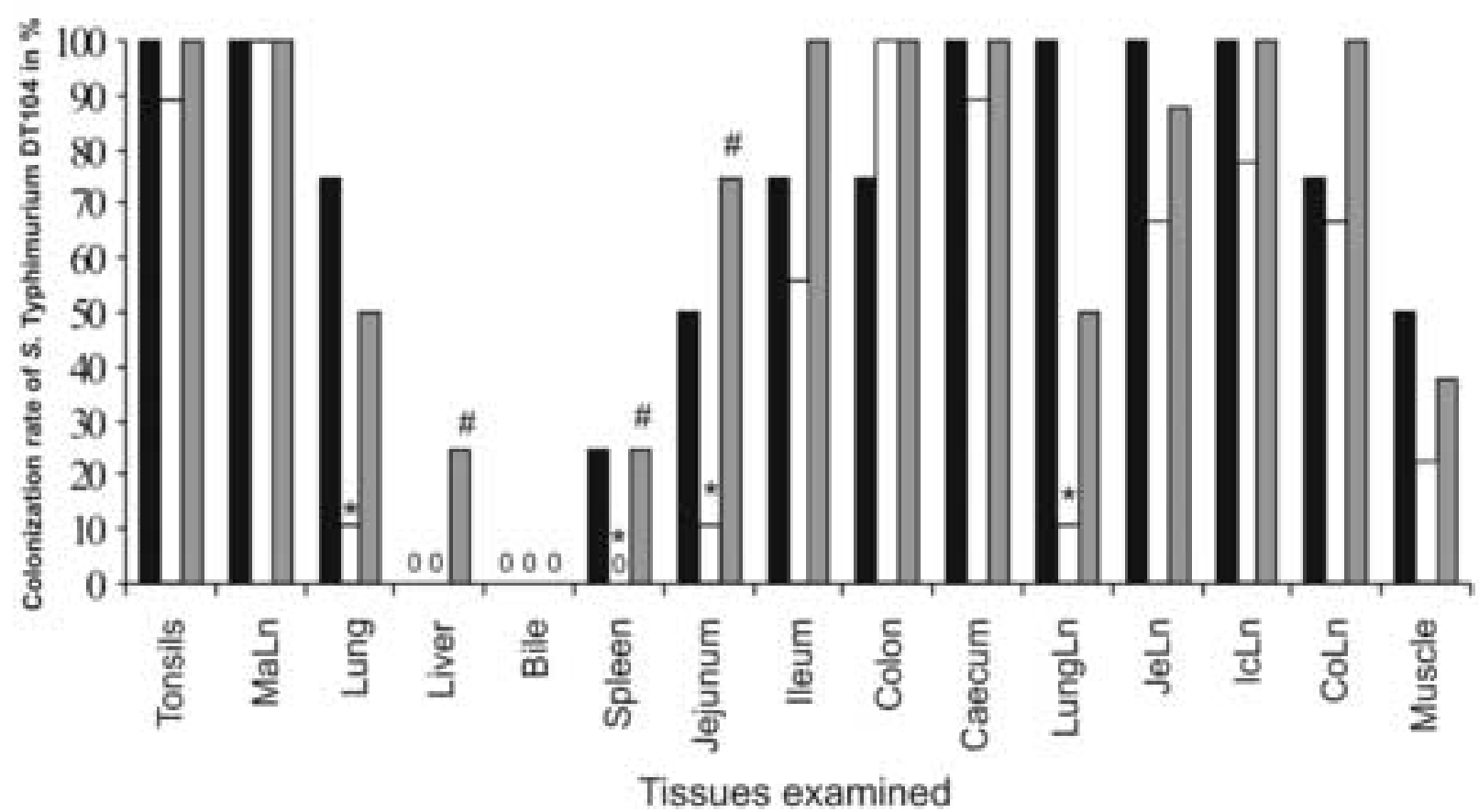




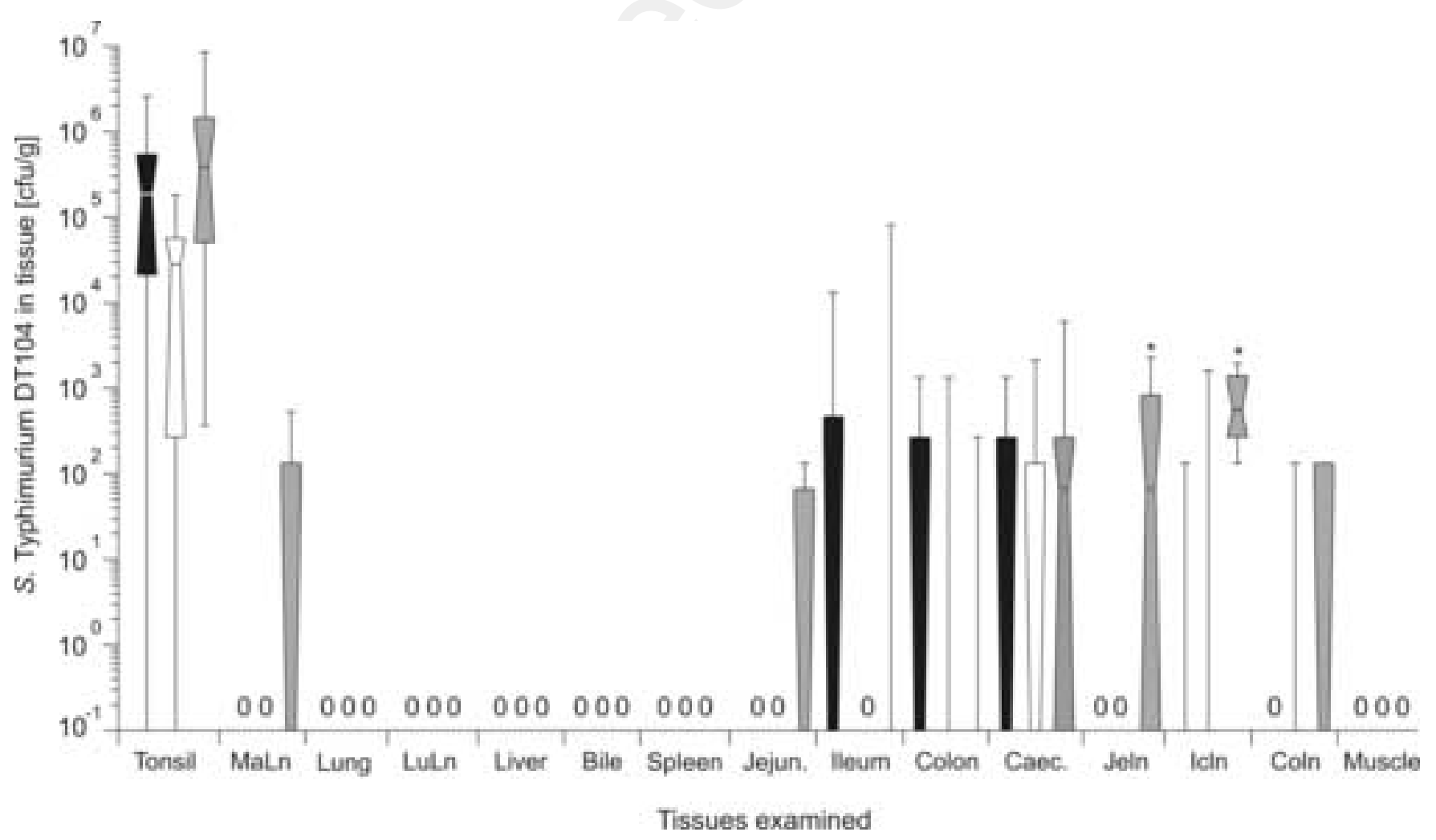

Page 26 of 30 


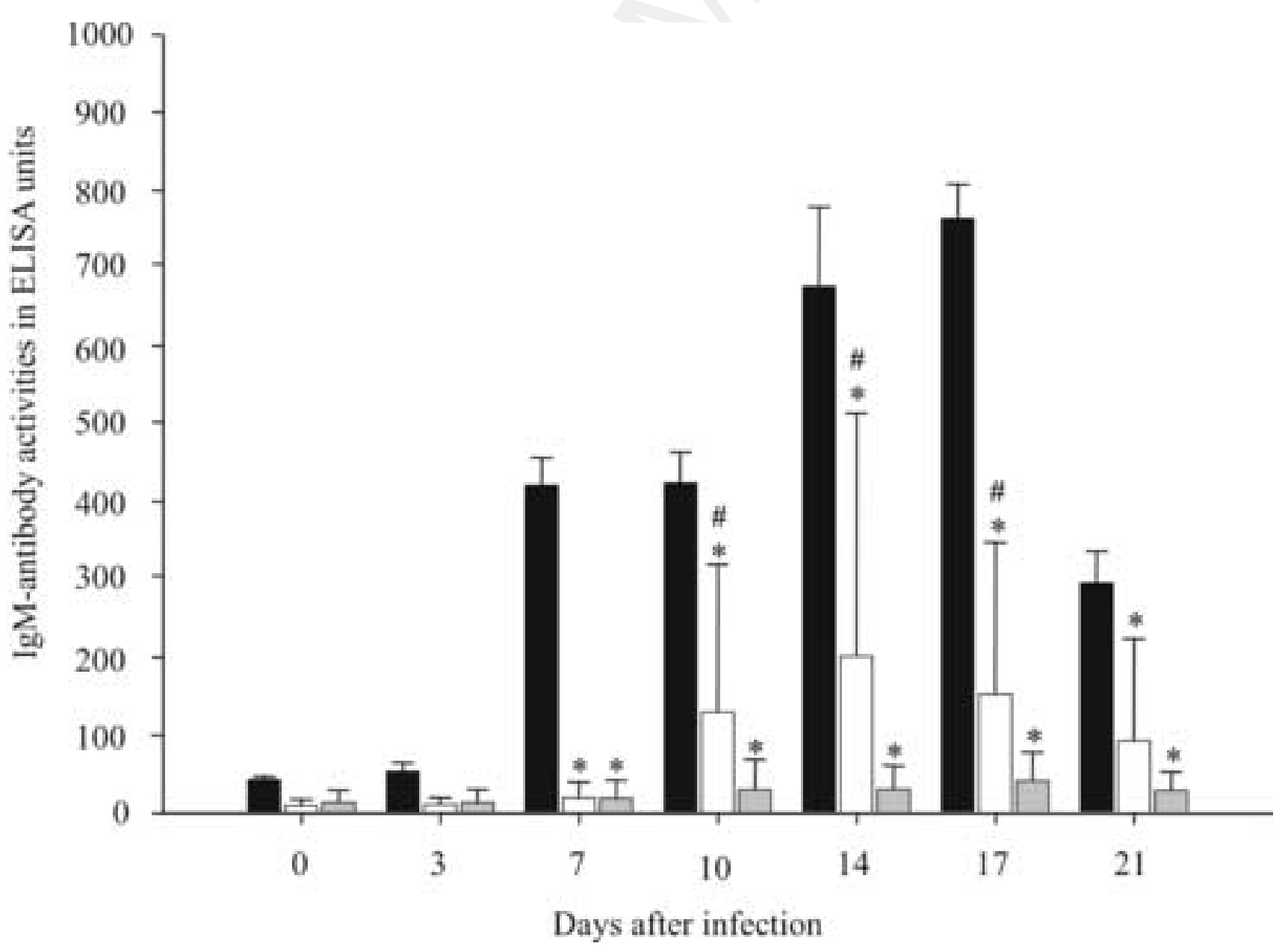

Page 27 of 30 

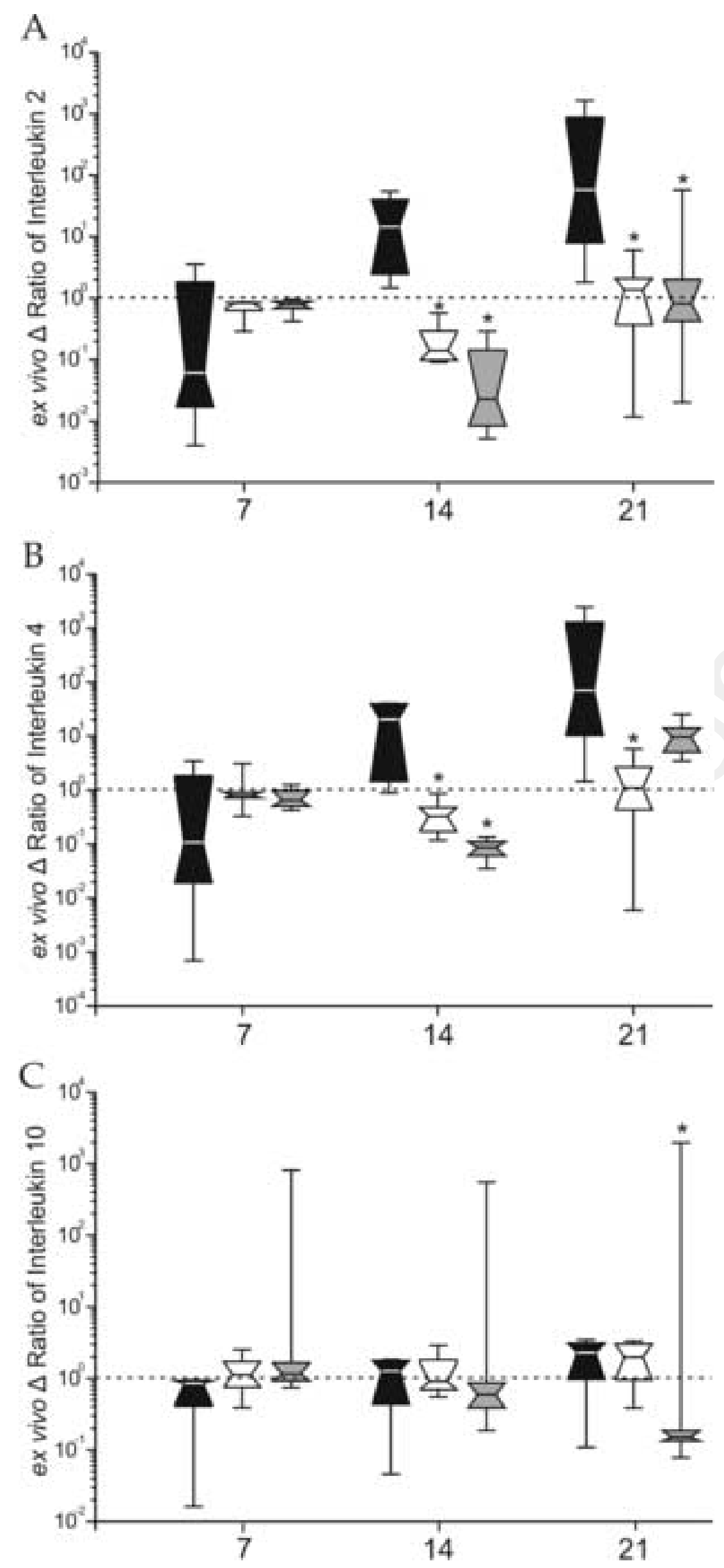

Days after infection 


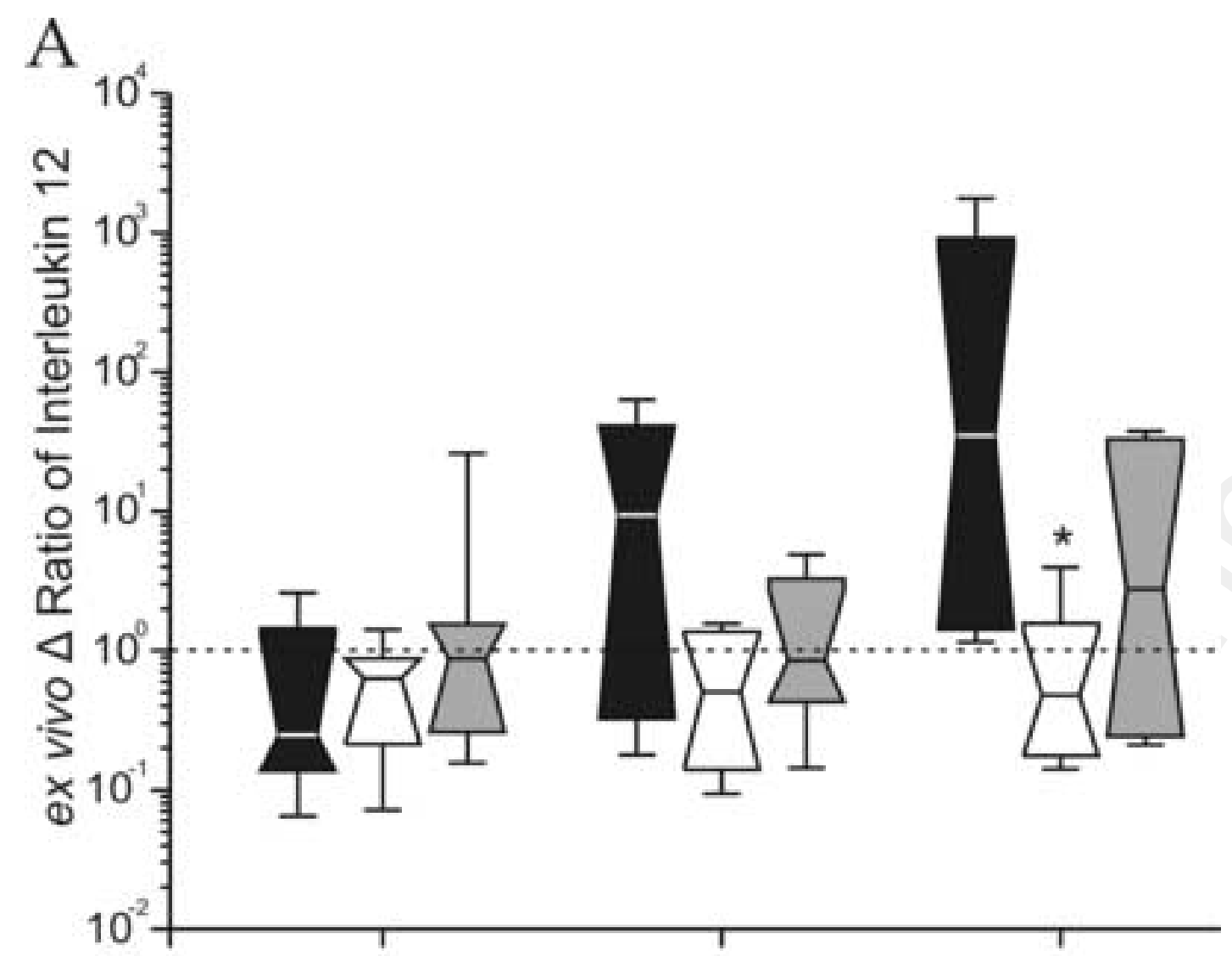

B

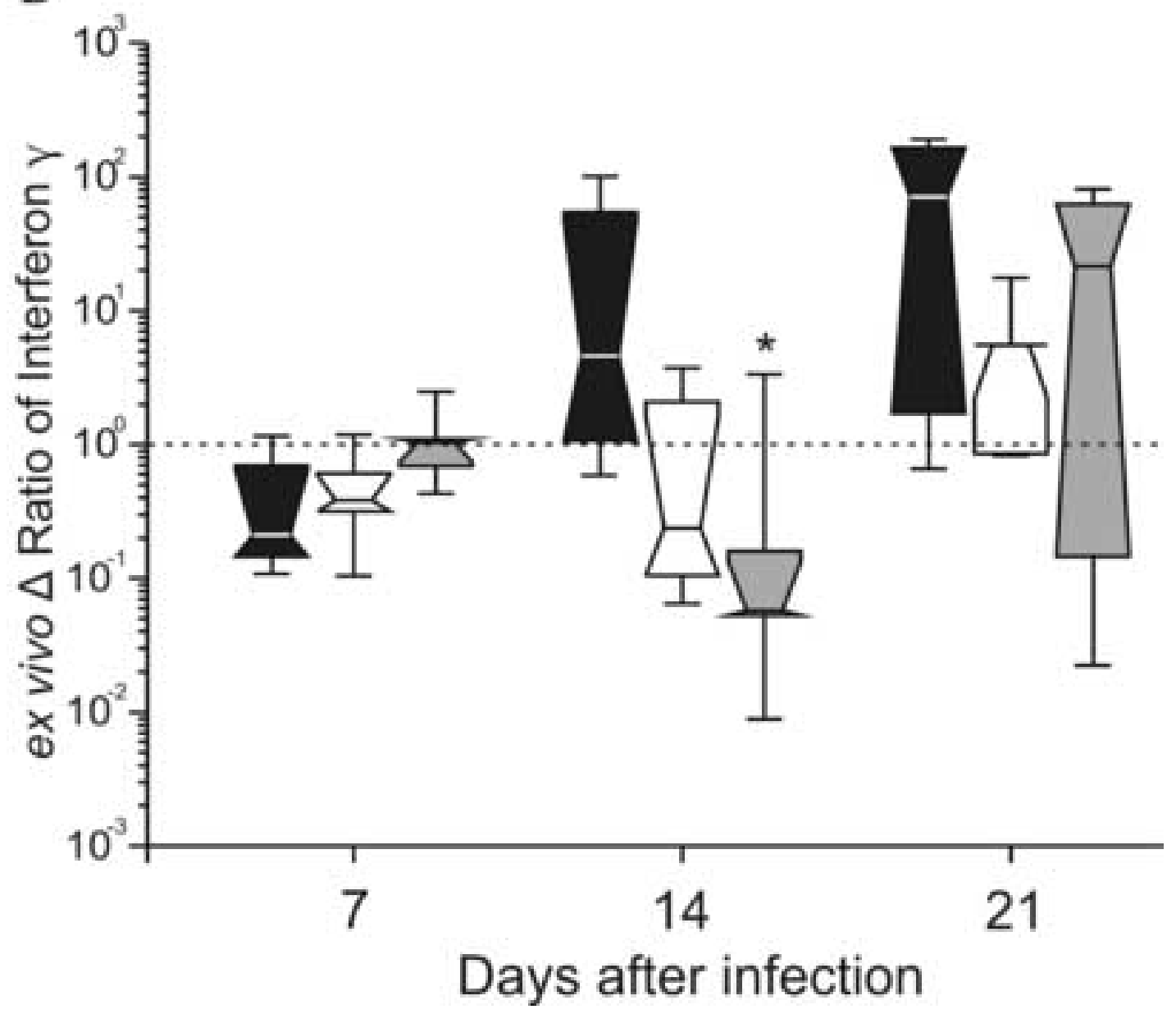




\begin{tabular}{|c|c|c|c|}
\hline Target & Forward primer & Reverse primer & Probe \\
\hline GAPDH & GAf (5'-gggctgc ccagaacatca-3’) & GAr (5'-tgtcatcatattttgcaggtttctc-3’) & GA ( $5^{`}-\operatorname{ccggcgctgc}$ caaggc tgt- $\left.3^{\prime}\right)$ \\
\hline IL-2 & IL-2f ( $5^{\prime}$-cagctcttgtgttgcattgca-3’) & IL-2r (5'-gcagcaatggctc cagttgt-3’) & IL-2 (5'-taacccttgcactcatggcaaacgg-3') \\
\hline IL-4 & IL-4f ( $5^{\prime}$-agaacacgacggagaaggaaa c-3’) & IL-4r (5'-ttgccatgctgctcaggtt-3') & IL-4 (5’-cttcggcacacacacg-3’) \\
\hline IL-10 & IL-10f ( $5^{\prime}$-cggcgctgtcatcaatttct- $\left.3^{\prime}\right)$ & IL-10r (5'-gagcttgctaaaggcactcttca-3`) & IL-10 (5'-tgtgaaaacaagagcaaggccgtgg- $\left.3^{\prime}\right)$ \\
\hline IL-12 & IL-12f (5'-cacagcagg cccaggaat-3') & IL-12r (5'-tgttgctgacggccttca-3’) & IL-12 (5'-tcaaccactcccaaaat- $\left.3^{\prime}\right)$ \\
\hline Gamma-Interferon & IFN- $\gamma f\left(5^{\prime}\right.$-gcgcaaagc catcagtgaa-3’) & IFN- $\gamma \mathrm{r}\left(5^{\prime}\right.$-tgcaggcaggatgacaattatt-3’) & $\operatorname{IFN}-\gamma\left(5^{\prime}\right.$-cagactatgtgcatca- $\left.3^{\prime}\right)$ \\
\hline
\end{tabular}

